\title{
MODELLING CULTURAL, NATIONAL AND INNOVATION IDENTITIES IN ORDER TO UNDERSTAND NEW ZEALAND'S MODEST INNOVATION PERFORMANCE
}

\author{
Tiffany Anne Rinne \& John Fairweather
}

\begin{abstract}
In a world that has moved swiftly to global trade, innovation rates have become one of the tools by which nations achieve success in the world. New Zealand is a middling international performer with regards to innovation. Utilizing discourse analysis and cultural consensus analysis we built models of New Zealand culture, national identity and innovation identity in order to gain insights into cultural and identity attributes that help and hinder New Zealand's level of innovation. Results show that while inventiveness is an important cultural trait, a trait based in New Zealand's history as a pioneering nation, there are other cultural factors such as a 'make do' attitude, the tall poppy syndrome, and an emphasis on lifestyle which potentially limit the innovation performance of New Zealand.
\end{abstract}

\section{INTRODUCTION}

In a world that has moved swiftly to global trade, innovation rates have become one of the tools by which nations and businesses achieve success in the world. Wind, Mahajan and Bayless (1990) show that new products, typically derived from innovation, explain one quarter to one third of financial growth in businesses. In many cases countries, businesses and organizations have an innovation imperative' in which innovation is deemed necessary for both growth and survival. These imperatives are paralleled by government policies which seek to encourage innovation in order to achieve economic and other goals (e.g., Oram 2001; OECD 2005). In contributing to knowledge about innovation, researchers have contended that culture is a significant factor influencing national rates of innovation (e.g., Nakata \& Sivakumar 1996; Shane 1992; Shane 1993). Understanding culture is therefore becoming increasingly important in efforts to support innovation. In this article we utilize discourse analysis and 
cultural consensus analysis to build models of New Zealand culture, national identity, and innovation identity in order to gain insights into cultural and identity attributes that may help and hinder New Zealand's level of innovation. We define innovation as a new idea, system, method or device that is brought to market.

Culture is hard to conceptualize and definitions abound. As this research draws on methods from cognitive anthropology, we will discuss culture as it has been conceived of in this field of study. Goodenough, an early cognitive anthropologist, believed 'Culture consists of standards for deciding what is,.. what can be... how one feels about it... what to do about it, and ... how to go about doing it' (Goodenough 1961:522). In other words, culture is the means by which people make sense of reality, that is, understand and organize objects, events and experiences. Essentially, culture provides society its rules. A popular theory used by cognitive anthropology researchers to assess these rules of society is schema theory. Schemata are abstract entities in the mind that can be combined to create models of the world that depict how societal groups organize and contextualize their experiences and understandings of the world. Using schema theory, culture can be placed in the mind (as opposed to the material world) and explained by analysis of the mind's components or schemata. Current trends in cognitive anthropology now look at how cultural schemata are linked to individual and societal actions (D'Andrade 1995). One set of actions of particular relevance to us is the origin and use of new technologies, in other words, innovation.

The relationship between culture and technology has been of increasing interest within Anthropology since the 1950s, when researchers began to look at the impacts of technology on culture in non-western societies (e.g., Godelier 1971). Since then, researchers have moved on to explore how culture influences technology. Anthropologists have looked at culture and its relationship to the uptake of technology in different areas of the world (e.g., Hasan \& Ditsa 1999; Herbig \& Miller 1992) as well as regional differences in innovation culture (e.g., James 2005; Saxenian 1994). Anthropologists have been well equipped to help decipher the contexts in which technology and science are situated, and the relationship between technology/innovation and culture has been a contemporary concern. According to Budka and Kremser (2004:222): 'The discipline of anthropology, with its particular methods and concepts, is predestined to investigate these new, highly dynamic spaces of socio-cultural interaction.'

In addition to anthropologists, other scholars have long contended that culture influences economic behavior (Smith 1776; Weber 1958), government poli- 
cies (Fukuyama 1995; Jin 2001) and national institutions and business systems (Fukuyama 1995; Geertz 1973; Hall 1990; Hampden-Turner \& Trompenaars 1993; Hofstede, Hofstede \& Minkov 2010; Jin 2001; Lipset 1990). Thus, it is not difficult to argue in principle that culture plays a key role in influencing innovation rates. The challenge is specifying how this occurs. In this paper, we go a step further from looking at culture's influence on technology uptake or regional innovation culture to look at how national-level culture may influence innovation at the national-level.

The value dimensions defined by Hofstede (1980) offer a measure of one component of culture (cultural values) and have been used by Shane $(1992,1993)$ and Rinne, Steel and Fairweather (in press) to explore the relationship between culture and innovation. Hofstede identified four criteria that reliably differentiate between cultural values in diverse nations. The first was individualism vs. collectivism. Individualistic societies have loose ties among their members and everyone looks after their own interests. By contrast, collectivist nations tend to have stronger ties between group members, and will place a higher value on communal interests than individual interests. The second dimension was large vs. small power distance. Power distance refers to the '...extent to which less powerful members of organizations and institutions (like the family) accept and expect that power is distributed unequally' (Hofstede \& Bond 1988:10). High power distance nations are more autocratic and individuals are more willing to accept differences in power and wealth. Strong vs. weak uncertainty avoidance is Hofstede's third cultural value dimension. This dimension is concerned with the manner in which cultures deal with an unpredictable future. The fourth cultural value dimension identified by Hofstede was that of masculine vs. feminine values. Masculine cultures place great value '...on achievement, tasks, money, performance, and purposefulness, whereas more feminine cultures emphasize people, the quality of life, helping others, preserving the environment, and not drawing attention to oneself' (Nakata \& Sivakumar 1996:64). For each country, Hofstede's dimensions were scored on a scale of o to $100 .{ }^{1}$

In Shane's (1992) cross-national research, low power distance and strong individualism were found to be linked to innovation success as measured by number of patents issued (holding wealth constant). In a follow-up study, using trademarks instead of patents as a proxy for innovation, Shane (1993) found that low power distance, strong individualism and weak uncertainty avoidance were linked to national innovation success (holding wealth constant). Shane's $(1992,1993)$ research indicates no relationship between masculinity and innovation. Shane (1993:70) contends: 'As organizational characteristics reflect 
societal values, managers might find that the organizational behaviours that promote innovation are easiest to develop in uncertainty accepting, individualistic, non-power distant societies, and these behaviours, in turn, might help to increase national rates of innovation.

Building on Shane's work $(1992,1993)$ but using more sophisticated measures of innovation, Rinne, Steel and Fairweather (in press) found Hofstede's cultural value dimension of power distance and individualism to be closely linked to innovation success as measured by the Global Innovation Index (GII) (INSEAD 2009). The results of Rinne et al. (in press) suggest that the degree to which a culture reduces the barriers between status levels (i.e., places a high value on egalitarianism) is, in some manner, connected to levels of innovation. Similar to Shane's research findings, Rinne et al. (in press) found no relationship between Hofstede's masculinity measure and innovation as measured by the GII.

Compared to the world average for Hofstede scores ( 55 for Power Distance, 43 for Individualism, 64 for Uncertainty Avoidance), New Zealand's scores on Hofstede's cultural values (22 for Power distance, 79 for Individualism, 49 for Uncertainty Avoidance) suggest that, from a cultural values perspective, New Zealand is in a good position to be innovative. New Zealand scores above average with respect to individualism and below average with respect to power distance and uncertainty avoidance. However, New Zealand is a mid-tier performer on various international innovation indices such as the GII (INSEAD 2009) and the International Innovation Index (III) (Andrew 2009). Further, within the OECD, New Zealand's GDP per capita is below the OECD average and in less than four decades New Zealand has slipped from the OECD upper decile to $23^{\text {rd }}$ position out of 31 (OECD 2010). Such slippage is usually considered as caused, in whole or in part, by a failure to innovate.

Nakata and Sivakumar (1996) examined the relationship between Hofstede's cultural values and the two component parts of new product development, initiation and implementation, and offer one means of explaining New Zealand's middling performance. Nakata and Sivakumar (1996) contend that high individualism, low power distance, low uncertainty avoidance and low masculinity are associated with success in the initiation stage of new product development. This pattern is similar to the New Zealand situation with respect to all dimensions but masculinity (World average for masculinity $=50$, New Zealand $=58$ ). By contrast, low individualism, high power distance, high uncertainty avoidance and high masculinity are associated with success in the implementation stage of new product development. These findings suggest that New Zealand would be good at the initiation stage of innovation (invention) but not the 
implementation phase, the result being lower than expected performance on international innovation indices.

Beyond large-scale quantitative survey-based research linking culture with innovation levels, a review of the literature reveals only one researcher (Smale 2008) utilizing qualitative methodologies to evaluate the associations between New Zealand innovation levels and cultural dimensions. Through purposive sampling of innovators and innovation experts, Smale found a number of cultural beliefs and behaviours which negatively affected national innovation levels. First, Smale found that innovators valued control and were risk averse, the result being a narrow capital structure. Second, Smale notes the presence of a tall poppy syndrome in which there was a tension between individualism and egalitarianism, which militated '... against the use of specialists and the emergence of champions' (Smale 2008:15). Third, Smale found that a satisficing mindset (satisficing refers to achieving adequacy as opposed to achieving optimization) was present, which combined with a narrow world-view, caused intellectual property protection to be improperly exploited. According to Smale (2008:7), 'A New Zealand centric world view acted as a barrier to deep understanding of markets. A once competitive advantage in practical do-it-yourself "make and use" innovation, often "borrowing" others' intellectual property, now represents a barrier to recognising, protecting and using the intellectual property for "make and sell"'. Fourth, Smale found a short-term orientation among innovators interviewed which acted as a barrier to accumulating the social capital necessary for innovation. Finally, Smale (2008:15) identified a lack of assertiveness and negative attitudes to failure which '... act as a barrier to learning and performance improvement.' It is relevant to note that these hurdles to innovation identified by Smale (2008) point to difficulties in innovation implementation not initiation, which support Nakata and Sivakumar's (1996) contentions that low power distance and high individualism nations, like New Zealand, will be better at innovation initiation rather than the implementation stage.

In this article, our goal is to present a more comprehensive picture of New Zealand culture than that identified by Hofstede and others, in order to better understand New Zealand's international position with respect to innovation and its middling level of performance. While these quantitative studies are enlightening in many respects, they do not allow for a particularly nuanced understanding of the New Zealand situation which would seem to be relevant since culture is a very complex entity. Building on Smale's (2008) research with innovators, we used cultural modelling and consensus analysis to look at how culture is conceptualised by members of the New Zealand public (i.e., people 
outside the innovation industry). Further, we used these methods to look at New Zealand national identities and innovation identities.

National identity derives from the image New Zealanders have of their country and the perceived or actual international image of the nation in world opinion (Rusciano 2003). National identity is important to study in the context of innovation because this is one area where culture manifests itself and becomes globally visible. In a global world, how a nation sells itself to and is perceived by the international community can have significant impact on the nation's economy. We define innovation identity as how New Zealanders recognize themselves as being innovative. We assessed New Zealand innovation identity in order to gain a clearer picture of New Zealand's strengths and limitations with respect to innovation.

The results of our analysis show that while inventiveness is an important cultural trait, a trait based in New Zealand's history as a pioneering nation, there are other cultural factors which potentially limit innovation performance within New Zealand. The cultural models derived from discourse analysis show the ways in which cultural values may limit innovation and we suggest that these values have not been given sufficient recognition in research and innovation policy to date. We acknowledge that factors other than culture affect innovation. Clearly, economic policy and the conditions of business in New Zealand may play a role. However, taking an anthropological perspective requires acknowledging that in addition to such contextual factors, culture can and does influence technology use and innovation. We build on this assumption by examining how cultural values may link to innovation.

\section{COMBINING CULTURAL MODELS AND CULTURAL CONSENSUS ANALYSIS}

Understanding culture and innovation requires an approach that can record the dominant and shared characteristics of culture. We chose to use a combination of methods - cultural models and cultural consensus analysis - that would achieve this goal in a relatively straightforward and efficient way. Cultural modelling is a qualitative method based on discourse analysis while cultural consensus is a quantitative method. Both types of methods have their strengths and weaknesses but these weaknesses can be lessened when both approaches are used in conjunction. The strength of quantitative methods is that they are easily reproducible and comparable across subject, time and academic disciplines - these are weaknesses of qualitative research. The strength of qualitative research is the insights it can provide regarding the '...dynamic interpretive process that takes form in cultural settings' (Garro 2000:312), something 
quantitative research cannot provide. The use of two different yet converging methods can aid in the development of '.. a more complete and representative model than is possible through the use of only one approach' (Garro 1988:99). Garro (2000) utilized consensus analysis and cultural models to study how the Ojibway, one of the the largest groups of First Nation people located in Canada and the United States, understood diabetes and its causes. According to Garro (2000:285) '... both cultural consensus and cultural models approaches could productively be applied in a converging manner to learn about underlying cultural knowledge and intracultural variation for a given topic.'

Cultural models are those presupposed, taken-for-granted models of knowledge and thought that are used in the course of everyday life to guide a person's understanding of the world and their behaviour (D’Andrade 1984). They are also the constructed representations made by researchers in order to describe shared knowledge and perceptions used by groups of people in their daily lives (Blount 2002; Cooley 2003). Cultural models systematically draw on personal discourse - the representations, practices and performances through which meanings are produced, connected into networks and legitimised (Gregory 2000). Discourse analysis allows researchers to get the insider's perspective on participant knowledge, thought and word meaning and considers complex subjectivities.

Cultural models are composed of linked and embedded schemata. An assumption of cultural modelling is that when individuals engage the world they do so in a simplified and focused manner that does not include all the detail and complexity of a situation (Holland \& Quinn 1987; Blount 2002). The Swiss philosopher and cognitive development theorist Jean Piaget (1926) first introduced the term 'schema' - which is defined as a mental representation of related perceptions, actions and ideas. He believed schemata to be the building blocks of thought (Woolfolk 1987). Drawing on concepts introduced by Piaget, Anderson (1977), an educational psychologist, developed schema theory to look at the process of learning. As a theory of learning, proponents of schema theory contend that knowledge is organized for each individual in an intricate complex of abstract mental structures representing one's means of comprehending the world. Since its introduction by Anderson (1977), schema theory has been adopted and modified to fit several fields of study, including anthropology.

Within anthropology Holland and Cole (1995) and Strauss and Quinn (1997) have been strong advocates of schema theory. According to Holland and Cole (1995), schemata are the constituent pieces that comprise cultural meaning. 
By first analyzing and then organizing the schemata identified via discourse analysis, cultural models of the world can be built (Strauss \& Quinn 1997; Blount 2002):

Once a text is created from discourse, one works 'backwards,' asking questions about how the text was created, in effect asking what the conceptualizations are upon which the text is based. The conceptualizations are the raw materials of the analysis. They reflect the agent's underlying mental models, the framework with which the world is engaged. The reconstructed mental models of an individual constitute the cognitive architecture upon which the discourse is generated (Blount 2002:9).

In essence, the task of discourse analysis and then cultural modelling is to identify the key components of thought and serialize, embed and hierarchically organize them into a coherent model. While models can be constructed based on findings from discourse analysis it is useful to obtain some measurement of the degree to which aspects of culture are shared. For this task we turned to consensus analysis.

Cultural consensus analysis is a quantitative-based methodological tool. It asks three primary questions (Romney et al. 1986). First, consensus analysis asks if shared knowledge of a specific cultural domain exists within a group of informants. Second, consensus analysis assesses the relationship of each informant's knowledge of the domain in question with the aggregate knowledge of that domain. Third, consensus analysis determines the 'culturally correct' answers to the survey questions without knowing or assuming the correct answers ahead of time. In other words, consensus analysis does not compare each subject's responses to survey items to an established answer key. Rather, the answer key, the content of 'culture', is estimated mathematically from the patterns of data.

Consensus analysis employs a kind of reliability testing, but on participants rather than on survey questions. The focus is on each participant, specifically on how they have responded to each question and how their responses across questions compare to the general pattern of other participant responses. It asks 'What is the relationship of each individual informant's command of the knowledge of the domain to the knowledge possessed by the aggregate?' (Swora 2003:343). Cultural competence refers to how much each individual informant 'knows' about a given domain of culture (Romney, Weller \& Batchelder 1986). Cultural competence scores for each person are estimated by factoring 
a matrix of person-by-person similarity coefficients. Thus, if a participant is estimated to have a cultural competence in a particular domain of 0.8 , he or she is estimated to command $80 \%$ of the knowledge of that domain. More 'expert' participants, those with higher cultural competence scores, agree with each other more frequently, and demonstrate greater cultural competence. The greater their competence, the more likely it is that their response is correct (for more details of this Bayesian inference process see Romney et al. 1986). Consensus analysis effectively chooses the 'correct' answer to a question by determining which answer maximizes the probability of obtaining the pattern of answers seen in the sample.

In summary, consensus analysis allows the researcher to operationalize findings by estimating the social distribution of knowledge, the 'culturally correct' answers to the questions, and the average knowledge possessed by each member of the informant pool. Thus, consensus analysis can contribute to cultural modelling by measuring the degree of sharing of cultural knowledge. In particular, it enables a researcher to determine if there is sufficient sharing in response to structured questions within and among groups to make it reasonable to infer that participants are drawing on a single cultural model (Romney et al. 1986). If the ratio between the first and second eigenvalue produced in the analysis is greater than three, the results suggest a single set of 'correct' answers and that respondents are drawing upon a single cultural model. If the eigenvalue ratio is less than three, the respondent group may be drawing upon one or more cultural models in answering the questions.

Consensus analysis, unlike more conventional statistical methods, requires very small sample sizes to reach statistical significance. This can be seen in work by Garro (1986), Swora (2003), Romney, Batchelder and Weller (1987) and Dressler, Balieiro and Dos Santos (1998) with samples ranging from ten to 20 participants. According to Weller and Romney (1988), sample size should be determined by focusing on three factors: the cultural competence of the participants, the confidence levels required, and the proportion of questions required to be classified correctly. Assuming an average cultural competence level among informants of 0.5 or higher, which seems reasonable given that we are assessing knowledge of culture broadly defined, and classifying 90 per cent of the questions correctly, a confidence level of 0.95 can be achieved using only 13 participants.

\section{SAMPLING AND PROCEDURE}

In order to use discourse analysis and cultural consensus analysis to construct 
models of culture, national identity and innovation identity we obtained a convenience sample of adult New Zealanders by approaching high schools in both Christchurch and Auckland and offering a payment of NZ\$45O in exchange for soliciting adult volunteers and providing a venue. A convenience sample was thought to be adequate for our needs because beliefs about culture and national identity are domains of investigation that should be widely shared across the nation, the extent of which we measured using consensus analysis. We chose schools from the largest cities by population on the North and South Islands of New Zealand - Auckland and Christchurch - as our research sites in order to account for possible cultural differences that might exist between the two islands.

Schools were selected from the mid-tier income bracket (New Zealand Decile 4-7). Contact with prospective schools was made by telephone and school representatives involved with fundraising were sought. The school representative was directed to source prospective participants, an equal number of men and women if possible, from people involved with the school or who lived in the lo$\mathrm{cal}$ area. Table 1 shows the demographic and socioeconomic breakdown of our sample. Most participants were over 40 years of age and classified themselves as New Zealand Europeans. No ethnic background was specified to schools for recruitment and our sample has only one Maori participant, one Indian and one Pacific Islander participant. Such a sample means that the results reflect the cultural viewpoint of New Zealand's majority population, New Zealand Europeans, rather than showing variation by ethnicity. As of the 2001 census, New Zealand Europeans comprised $69.8 \%$ of the population. Future research could explore variations in cultural expression in New Zealand's minority ethnic groups as well as in a more diverse range of ages.

In our research we obtained participant discourse using either computer-assisted self interviews (CASI) or face-to-face interviews (FTFI). Both CASI and FTFI were utilized because a secondary objective of our research was to assess the quality of data obtained via FTFI and CASI to see if they were similar. For open-ended questions of the nature used in this research, FTFI has long been the standard as it is believed that the interviewer can help guide participants through the interview process by asking questions to clarify unclear responses and questions to delve deeper into the subject matter. However, by using CASI, researchers can reach a larger sample of respondents more efficiently compared to FTFI. Instead of face-to-face interviews conducted over weeks or months, a researcher can gather respondents in a computer lab at a single sitting. In addition, by using CASI a researcher can avoid the cost and time of transcribing recorded responses. Our findings, presented in Fairweather 
Table 1. Participant Demographic and Socioeconomic Information

\begin{tabular}{l|c|c}
\hline & $\begin{array}{c}\text { Christchurch } \\
\mathrm{N}=20\end{array}$ & $\begin{array}{c}\text { Auckland } \\
\mathrm{N}=20\end{array}$ \\
\hline Age & - & 3 \\
\hline $20-29$ & 1 & 1 \\
\hline $30-39$ & 13 & 10 \\
\hline $40-49$ & 6 & 6 \\
\hline 50 & &
\end{tabular}

\section{Education}

\begin{tabular}{l|c|c}
\hline University Degree & 5 & 10 \\
\hline Some Uni & 1 & 4 \\
\hline Tradeschool & 3 & 3 \\
\hline High school & 11 & 3 \\
\hline$<$ High school & - & - \\
\hline
\end{tabular}

Total Income

\begin{tabular}{l|l|l}
\hline$<49,999$ & 1 & 1 \\
\hline $50,000-99,999$ & 9 & 9 \\
\hline$>100,000$ & 6 & 8 \\
\hline
\end{tabular}

Ethnicity

\begin{tabular}{l|c|c}
\hline New Zealand European & 19 & 18 \\
\hline Maori & 0 & 1 \\
\hline Pacific Islander & 1 & 0 \\
\hline Indian & 0 & 1 \\
\hline
\end{tabular}

and Rinne (under review) show that both methods of obtaining participant discourse produced models with the same cultural elements.

The qualitative interview portion of our research took on average one and a half hours and was scheduled in advance at a designated time and place (namely onsite at the schools) and outside of normal daily activites. The researcher began each interview by clarifying its purpose and explaining that participants would be asked questions about three domains: culture, national identity and innovation within New Zealand. Participants were assured that there were no right or wrong answers to any of the questions and we asked that they speak freely about their beliefs and opinions. A total of 50 open-ended 
questions were asked. For each domain of interest we asked a number of wide ranging questions. For the domain of culture we asked about important cultural symbols, important figures representing true New Zealand ideals, historical happenings that have influenced culture, words one would use to describe New Zealand culture, colloquial sayings of cultural relevance, the importance of science and technology within New Zealand culture etc. For the domain of national identity we asked about how participants believed New Zealand was identified internationally, how they would characterize national identity as a citizen of New Zealand, in what ways they believed New Zealand was better than other nations and also not as good, achievements on the world stage that have influenced New Zealand national identity, words they would use to describe national identity etc. For the domain of innovation we asked about how New Zealand's history has influenced innovation, what characteristics of New Zealanders made them good at innovation, ways in which their workplace was innovative, where most innovation in New Zealand occurs, the ease of bringing an invention to the market, factors which would drive a person to innovate, significant sectors, companies and products which have been innovative etc.

In order to analyze the discourse obtained during the interview process (either computer based or personal interviews), each interview text was imported into NVivo 7 and coded according to key words and phrases. It was then inductively analyzed for patterns, structure and linkages of schemata. The resulting cultural models demonstrate how our participants perceived New Zealand cultural, national and innovation identities.

Following the open-ended questions, participants were asked to complete a series of Likert-type scales ${ }^{2}$. The Likert questions dealt with generalized aspects of culture and national identity. Regarding culture, participants were asked 'For New Zealanders as a whole, how important are each of the following items of New Zealand culture?' Items included: religion, culinary traditions, music, dance, technology, outdoor activities (tramping, fishing etc.), playing sports, viewing national and international competitive sports, rural living, urban living, fashion, inventiveness, a common language, a shared set of values, environmentalism, ethnic identity, the arts (painting, literature etc.), architecture, and shared history. These elements were chosen as they represent commonly studied aspects of culture within anthropology and reflect a range of cultural elements. For national identity, participants were asked 'For New Zealanders as a whole, how important are each of the following items to New Zealand's national identity?' Items included: achievements in sports, the way democracy works, achievements in the arts, economic achievements, the armed forces, political influence on a world stage, scientific achievements, technological 
achievements, fair treatment of ethnic groups, contribution to world history, international peacekeeping efforts, environmental consciousness, the natural landscape, and unique cultural values. These elements were chosen based on a review of the national identity literature. Each element represents a key way in which a nation can differentiate itself from others in the world.

We achieved our research goal to obtain 20 participants from each of the two high schools, one in Christchurch and one in Auckland. Consensus analysis can be successful with sample sizes ranging from ten to 20 . Our sample of 20 people in each city exceeded the minimum sample size and allowed for a more in-depth inquiry into perceptions of innovation and culture.

Our initial sample size goals were tentative estimations of a sample size thought necessary to achieve informational redundancy within the discourse analysis while also meeting the sample size criteria for consensus analysis. Had information redundancy not been achieved (i.e., new data was still being generated as the sample size reached 20) further sampling would have been conducted. It should be noted that although our samples were adequate in terms of size they may be limited by the fact that most of the parents were within the 40-49 age bracket which is higher than the median age for New Zealand men of 35.6 years and women of 37.8 years (Statistics New Zealand 2011). It is, however, unlikely that a ten year differences in age would have a significant effect on cultural beliefs, especially when one considers that older people as bearers of culture, have had more time to 'learn' cultural patterns.

\section{MODELS OF CULTURAL, NATIONAL AND INNOVATION IDENTITIES}

The discourse and consensus analyses yielded models of New Zealand culture (Figure 1) and national identity (Figure 2) as well as a model of New Zealand innovation identity (Figure 3 ). These three models were used to formulate a fourth model: cultural limits to innovation (Figure 4). It should be noted, that neither discourse analysis nor consensus analysis indicated significant cultural differences between the North and South Islands of New Zealand, thus, the results presented in this section represent findings from the two samples taken as a whole.

At the base of participants' view of their culture was the idea of New Zealand as multicultural (Figure 1). Participants often mentioned the signing of the Treaty of Waitangi as a significant historical event for New Zealand with the treaty seen as linking Maori and Pakeha into an uneasy union. Pakeha participants spoke of Maori/Pakeha disputes over land and needing to be politically cor- 
rect in dealing with the Maori due to past injustices against the community. Although the relationship was characterized as uneasy, participants often mentioned Maori symbols, such as the koru and tiki, as being important symbols for New Zealand. The Maori were seen as very much a part of general New Zealand culture.

In addition to this idea of an uneasy multicultural blend, participants saw themselves as a culture in which emphasis is given to lifestyle, sports, an outdoorsy orientation and pioneer values. Regarding lifestyle, New Zealand was seen as a playground with beautiful scenery and place where everyone was treated equally. The following is a representative comment regarding the significance of lifestyle in New Zealand culture:

New Zealand is safer. Greener. The quality of life is good. The first time I saw the amount of homeless people in San Francisco I was unprepared. We've got a few people who live on the streets but nothing compared to what I saw there. There's more opportunity here. You're not one of millions and millions. You're one of a few million. There's also a whole variety of country here. There is easy access to the outdoors, mountains, rivers, streams (Female, 41 years of age).

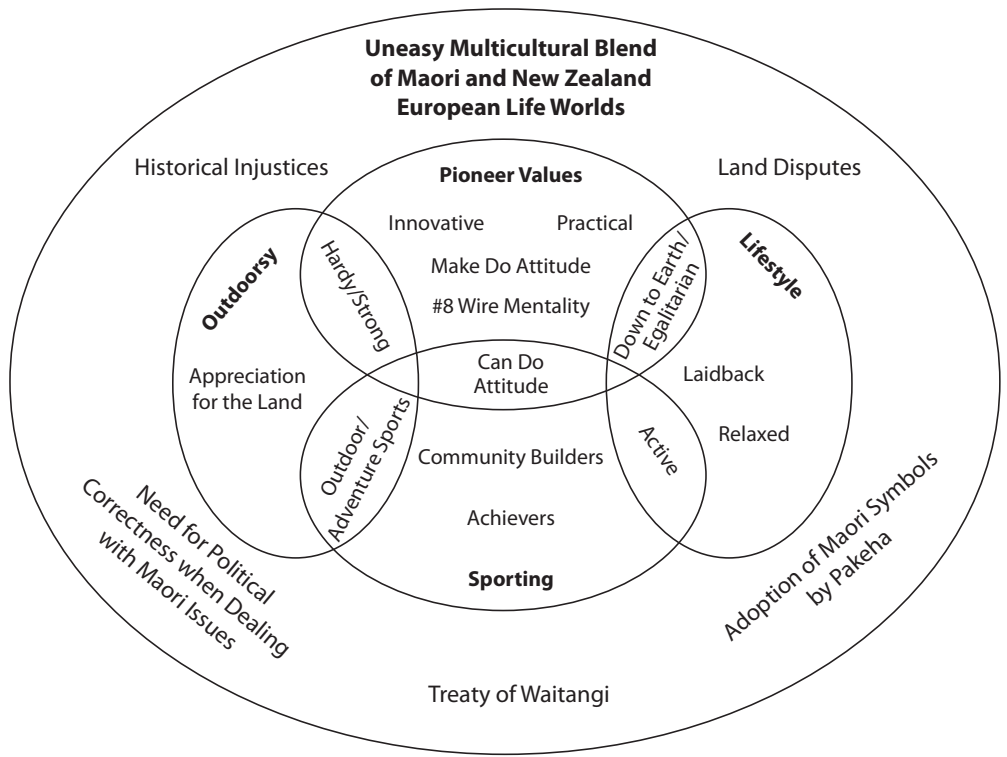

Figure 1. New Zealand Cultural Identity 
Sports such as rugby and other outdoor activities like tramping and sailing were seen as particularly important to New Zealand culture. They were seen as community builders and a way for New Zealanders to get out and enjoy New Zealand's beautiful landscapes. Regarding sport, one participant said:

It's part of our everyday life. We either participate through doing or participate through watching. There aren't many households that wouldn't be tuned into the All Blacks playing or the league finals. Or whatever particular sport they are involved in. I know our kids have always grown up playing a range of sports and we would always encourage them to do that. We have quite an active lifestyle rather than say Americans who live in apartments and sit there watching TV and going to their computers. On the way here I saw my six year old out on her roller blades. The older kids I know would be off bike riding or doing sports practice. It's a very big part of our everyday life. That's not different from what a lot of average Kiwi's would do (Female, 41 years of age).

Regarding sport as a community builder, participants said:

Somehow or other its gotten built into the culture. Again people settled out here and maybe it was people needing to get together and do something (Male, 51 years of age).

Rugby has always been at the center of small communities and has sort of brought people together. Whether it be in local town rugby or in the city suburbs (Male, 50 years of age).

With respect to the outdoor orientation, participants felt a close connection to the New Zealand landscape and felt it was important to get out in nature and do things like hike, sail etc. Participants said:

I like living in New Zealand because you can be one day in the mountains and the next day at the beach. We travel a lot around the South Island. On a whim last weekend we took the kids up to the snow. Last night we were paddling in the river (Female, 41 years of age).

I like our landscape. We're not overcrowded. We've got easy sea and mountain access. I like to get out there (Female, 54 years of age).

Participants saw their culture as being inventive/innovative and this was linked 
to the days when New Zealanders were a pioneer people. New Zealand is small and geographically isolated. Early pioneers were strong and had to make do with what they had available in order to survive and thrive. The small size and isolation of New Zealand is believed to have been responsible for the inventive/innovative nature of New Zealanders to the present day. For example, participants said:

There's a \#8 wire mentality. People had to cope a long way from home. They lacked resources and infrastructure and had to find a way to do what they had to do. I'm sure that mentality is still hanging around (Male, 51 years of age).

So there are all those things that have come out because of necessity and there not being equipment and that's created innovation and that all comes back from being so far removed from the rest of the world (Female, 76 years of age).

It should be noted that the way participants saw New Zealanders as being innovative differs from our definition of innovation - to bring a new idea, system, method or device to market. Instead, it refers more to being able to 'think outside the box'.

The results of cultural consensus analysis provided additional support for the findings from discourse analysis. Cultural consensus analysis of the Likert exercise data indicates that outdoor activities, playing sports, viewing competitive sports, environmentalism and a shared set of values were very important for most New Zealanders. Unfortunately, the lifestyle elements we chose to include in the Likert exercise (urban and rural living) did not encompass lifestyle as it was discussed in the interviews (i.e., laidback, egalitarian, familyoriented, active). It is our belief, however, that had 'lifestyle' been included in the Likert exercise, it would have been identified as a significant component of New Zealand culture as it was a dominant theme within the discourse analysis. Although not included in the exercise, it should be noted that in the model of culture (Figure 1), the lifestyle element overlaps with the pioneer values and sporting elements, which were included in the Likert exercise and were deemed important by participants.

At the base of participants' perceptions of New Zealand national identity was the image of New Zealand as a small, isolated island nation with a low population (Figure 2). Being small, both in population and land area, as well as isolated, made sports, lifestyle and landscape all the more significant for 
the New Zealand participants. Sports were seen as a way to be present on the world stage. Participants believed that New Zealanders 'punched above their weight' in sport, and had a high level of achievement for such a small country.

Sport was considered an important source of national pride. Representative comments include:

A huge role. There is an expectation that we are a sporting nation. Em, its led to a self-belief. Increased our self-belief. Increased our identity on the world stage. Made us a healthier nation because there is that expectation. It's almost part of the socialization in our society (Female, 45 years of age).

Very significant as it shows us off to the world stage that we are so little but can compete against countries that have more money and players and sometimes we even beat them which gives New Zealanders a great sense of pride (Female, 32 years of age).

The lifestyle afforded to those living in New Zealand and the landscape were also sources of significant pride for participants. The New Zealand lifestyle was believed to be relaxed and family-oriented. Participants appreciated the egali-

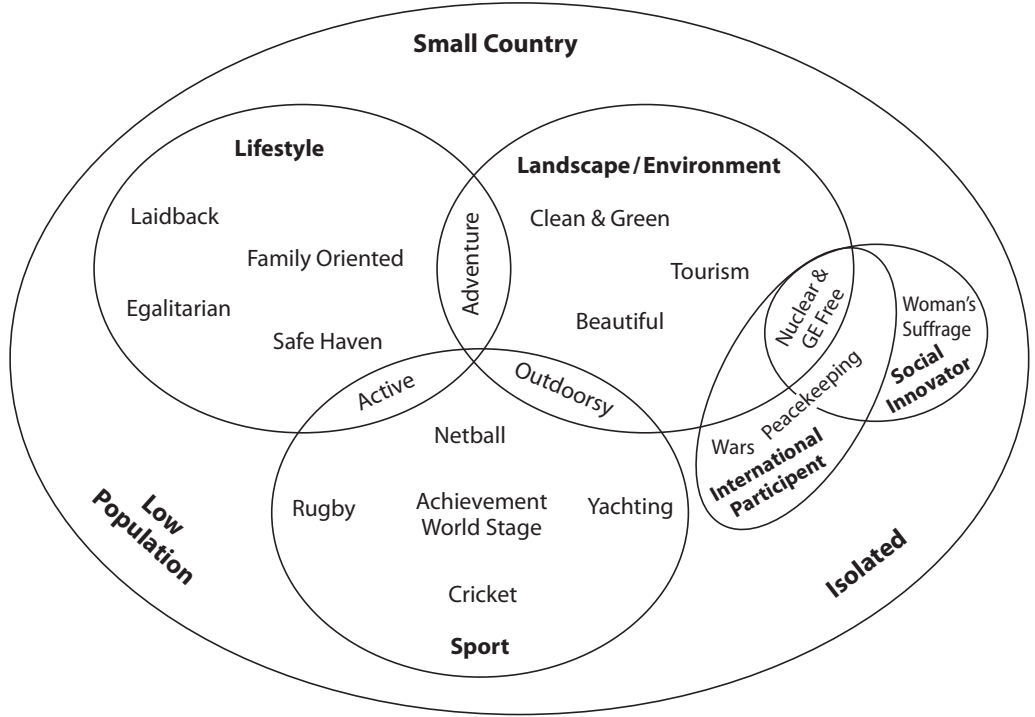

Figure 2. Model of New Zealand National Identity 
tarian nature of New Zealand society and felt that no one stood above another. Being isolated afforded participants a sense of safety. New Zealand was considered far removed from many of the world's problems and a safe place to raise children. The close proximity of the ocean and mountains also contributed to the New Zealand lifestyle by serving as playground venues for 'outdoorsy' New Zealanders. They were seen as places for adventure. Participants appreciated New Zealand's beautiful, clean and green landscapes and it was seen as one of the factors which set New Zealand apart from other nations - made it unique. Tourists came to see a landscape only New Zealand could offer.

Although not as significant as sport, lifestyle and landscape/environment, participants also believed part of New Zealand national identity was New Zealand as social innovator and New Zealand as international participant. With respect to being a social innovator, participants were very proud of the nation's no nuclear stance, previous prohibitions and overall level of cautiousness in dealing with genetically engineered food and crops, and the fact that New Zealand was the first nation in the world to grant women the right to vote. Representative comments include:

Well we've always been very forward in the world stage of policy making and world health. Helen Clark is in charge of funding for the UN. New Zealand has always had somebody working in the UN or other big institutions. So it's very well, involved, I think, in world politics (Female, 76 years of age).

Our Nuclear-Free stance. Yes it is an important factor because it promotes the idea if a small country like New Zealand can make this gutsy decision, so can the rest of the world (Female, 55 years of age).

New Zealand being the first country to give women the vote in 1891. Until recently we had a woman Prime Minister (Female, 55 years of age).

In addition to their role as a social innovator, New Zealanders were proud of the nation's conduct within the international community. Participants often spoke of the nation's peacekeeping roles abroad and although a small nation, participants felt pride that New Zealand was involved in the international community, as illustrated by:

It's important to be involved in the international community as a player. It's very important for politics, for New Zealanders to be seen 
by the rest of the world as being out there and saying yes we are here to be counted (Female, 57 years of age).

I think we have been acknowledged for our involvement with the international world when it comes to involvement with aid and peacekeeping (Female, 41 years of age).

The results of cultural consensus analysis provided additional support for the findings from discourse analysis. Cultural consensus analysis of the Likert exercise data for national identity indicates that achievement in sports, natural landscapes, and environmental consciousness are the three top elements of national identity (of those elements included within the Likert exercise) for most New Zealanders. As was the case with the cultural elements Likert scale, a lifestyle element was not included on the national identity Likert scale but similarly, it is our belief that had it been, it would have been identified as a significant component of kiwi national identity as it was a dominant theme within the discourse analysis. It should be noted that innovation and being inventive were not considered a significant component of New Zealand national identity as identified by participants in both the discourse analysis and on the Likert scales.

In terms of innovation identity, discourse analysis of interview texts showed that participants believed most Kiwis' had a 'Can do attitude', could make something out of nothing (\#8 Wire Mentality), and were good at 'Thinking outside the square' (Figure 3). Participants believed a majority of invention/ innovation in New Zealand occurred in the backyard shed - a man tinkering in his spare time - as opposed to in businesses or at universities. The 'man in his shed' image was viewed as a holdover from the country's pioneering days. The drive to invent or innovate is believed to be based not in monetary gain but rather in seeing a need and being able to do something about it. Regarding innovation within New Zealand, participants said:

We're down to earth with a can do attitude. Isolation of the immigrants who colonized New Zealand required a creative sense of living and self preservation. Our fore fathers relied on innovation to survive in a country many miles from any other civilisation (Female, age undisclosed).

I think the main factor driving someone to innovate is seeing a need. Either a personal need or a business need. To see the possibility of it being innovative (Female, 51 years of age). 
For me to invent something would be for the benefit of others and sometimes, in some people, that is more satisfying than the money (Male, 68 years of age).

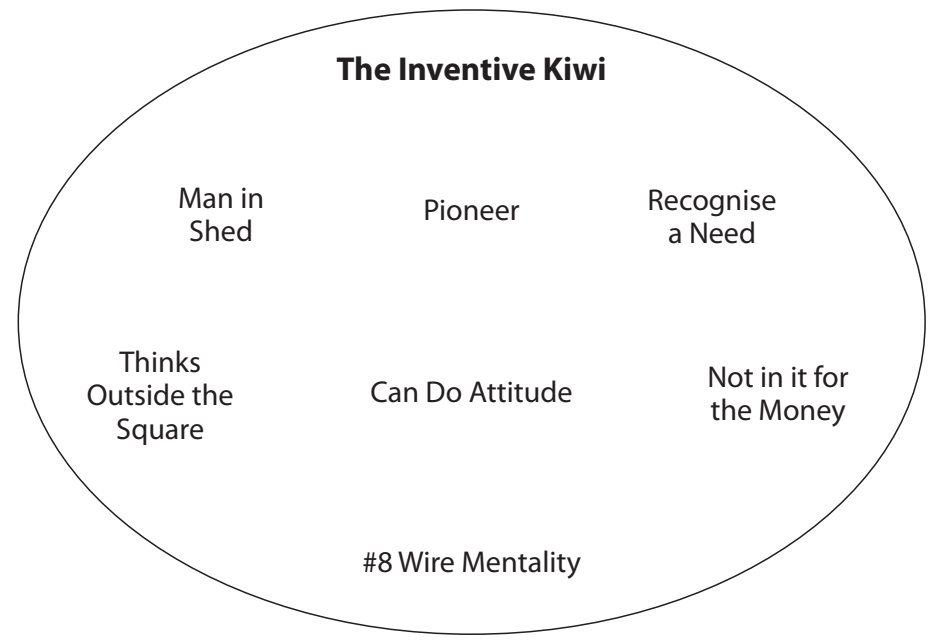

Figure 3. Model of New Zealand Innovation Identity

\section{CULTURAL LIMITS TO INNOVATION}

The overarching goal of our research was to go beyond previous studies linking culture and innovation - studies that relied on quantitative measures of both culture and innovation - in order to gain an understanding of New Zealand's unique innovation situation and to offer an explanation for the modest levels of innovation. Further, we built on Smale's (2008) work with innovators by looking at culture as perceived by everyday New Zealanders and by also looking at New Zealand national identity and innovation identity.

Participants believed that pioneer values dominated within New Zealand. These values included 'a can-do attitude,' 'egalitarianism,' \#8 wire mentality' (ability to make something out of nothing), practicality and strength. Given the cultural belief that New Zealanders are indeed inventive, why then does New Zealand not do better internationally with respect to innovation? We believe the answer to this question lies, in part, with the national culture of New Zealand. We make two sets of observations about the results. The first relates to a simple comparison of the models of New Zealand culture and national 
identity, while the second builds on this comparison to derive a model of cultural limits to innovation.

A comparison of the model of New Zealand culture and the model of New Zealand national identity shows that there is an absence of inventiveness and innovativeness in New Zealanders' model of national identity except with respect to social innovation (e.g., women's suffrage, nuclear-free etc.). Despite believing themselves to be inventive, as part of their pioneer value set, participants did not include invention or innovation (defined to the respondent as a new system, method or device that is brought to market) as a component of how they, as citizens, viewed their national identity. Inventiveness was seen as part of culture but not national identity. What is more relevant to national identity is sport, lifestyle and landscape/environment. These are seen as areas where New Zealand excels in the world (stands above others). Participants did not believe New Zealand excelled with respect to innovation. When asked, respondents could name few innovative New Zealand companies, few New Zealand inventors and few areas where New Zealand might be internationally known for being innovative in terms of business and market economies. New Zealand innovation as represented by prominent industries, companies and people appears to not have captured the public's attention.

By analysing models of New Zealand cultural, national and innovation identities, we were able to identify aspects of New Zealand culture that may limit innovation (Figure 4). It should be noted that the material presented in Figure 4 is our view of cultural limitations to innovation, and not necessarily that of our respondents. Further, we do not contend that culture is the only limiting factor in New Zealand innovation. The structure and conditions of business in New Zealand as well as government policies undoubtedly play an important role in New Zealand innovation success and failure. We do, however, contend that culture is a significant influencer of New Zealand innovation and therefore offer our view on cultural facets that potentially limit it.

First, as part of New Zealander's pioneer value set, there is widespread belief that people can make something useful out of anything but are also willing to make-do with less than the best. A make-do attitude need not be beneficial for innovation as it can lead to production of products to a subpar standard and can lead to the abandonment of innovation ideas if too many obstacles arise during the innovation process. Inventors may be satisfied with using the invention only for their own needs rather than taking it to market. Second, egalitarianism and a general down-to-earth attitude are highly valued in New Zealand. The result has been a reaction known as the Tall Poppy Syndrome in 


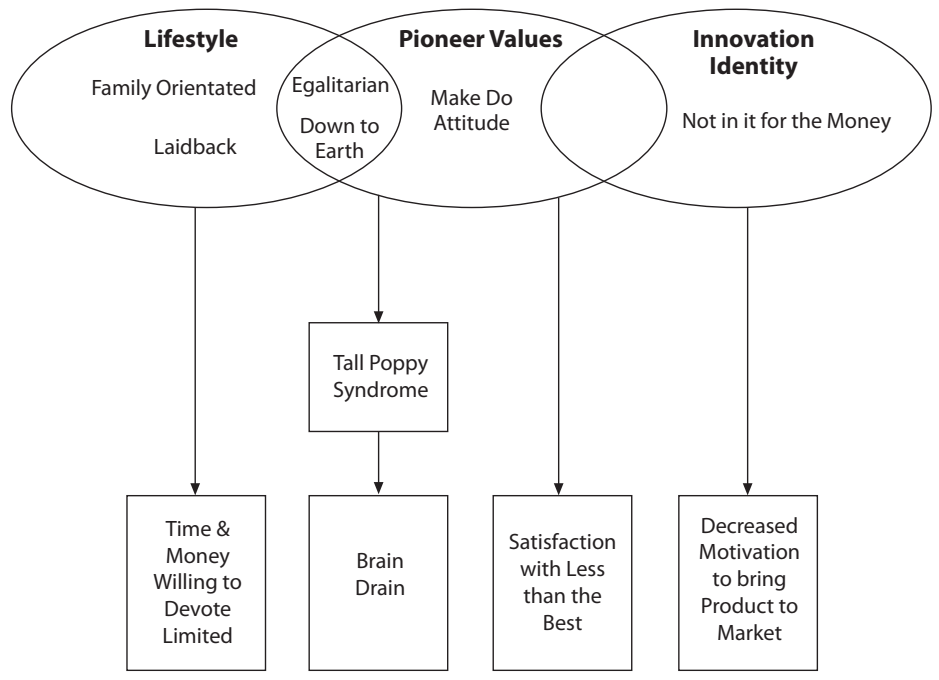

Figure 4. Model of Cultural Limits to Innovation

which 'tall poppies' or those standing above the crowd are frowned upon or cut down. We believe this syndrome may be linked to a brain drain within New Zealand in which high academic or business achievers, those that are likely to be successful innovators, leave the country, in part, because they are underappreciated, thus decreasing the pool of New Zealanders with the necessary skills to bring an innovation to its end stage. ${ }^{3} \mathrm{~A}$ third limit to innovation is New Zealand's lifestyle orientation. New Zealanders tend to value time spent with their families and in leisure activities more than they value business success or money. Thus, they limit the time and money they are willing to devote to innovation activities. Related to this is the idea that many innovators are not in it for the money. Money is a form of reward one receives when an innovation reaches the market. With the end goal not being a monetary reward, inventors may feel little drive to take their product to market, instead being satisfied to use it for their own purposes. For New Zealanders there may be other values besides money that define success and these in turn may be redefining the parameters of innovation such that they differ from our definition, which involves bringing the product to market.

Regarding our findings, it is important to note that our sample was dominated by individuals in their 40 s. It may be the case that this age group, an age group more likely to be financially settled and secure compared to those in their $20 \mathrm{~s}$ 
and 30s, no longer possess the same drive for financial reward as their younger counterparts and may not see the drive in others. Alternatively, this age group would have better resources to invest in invention and commercialisation. As previously mentioned, future research could expand the sample to include a wider age range.

The dominant cultural beliefs found in our sample suggest that New Zealanders may be good at technology user innovation (modifying existing technology to suit one's needs) and small-scale innovations (those that can be completed by a single person working alone with limited resources). However, aspects of New Zealand culture do not strongly nurture the process by which inventions become popular and commercially successful innovations. Further, it may be the case that these forms of invention go unrecognized on international innovation indices such as the GII and III as they are hard to directly measure. For example, in reviewing the literature, we found no documentation of the prevalence of technology user innovation within New Zealand.

In our study of New Zealand culture as seen through the eyes of Pakeha New Zealanders, we identified some of the same limits to innovation as Smale (2008) in his sample of innovators. Smale noted a 'make and use' mentality as opposed to a 'make and sell' mentality. This corresponds well with our findings highlighting the pioneer mentality of making something out of nothing but the absence of being in it for the money and taking it to market. Further, Smale reports a satisficing mentality, which mirrors our 'make do' attitude identified by cultural modelling. Smale also identified the presence of a tall poppy syndrome, which he believed blocked the presence of innovation champions. Our findings are consistent with his claim. Further, our findings reinforce those of Nakata and Sivakumar (1996) who argue that New Zealand's cultural values suggest that New Zealand would be better at the initiation stage of innovation (invention) than the implementation stage (bringing the product to market).

Although our results are insightful about the New Zealand situation, we recognize that further insight can be garnered via comparison with other countries. To this end, we are seeking to replicate the method used here in Europe and the United States. We have collected data from Estonia, Slovenia, the Czech Republic, Sweden, Finland, Denmark, Austria, South Korea and Australia.

CONCLUSION

Our results suggest that the cultural limits to innovation identified by Smale (2008) for innovators extend to the larger New Zealand European populous. 
We have also identified that innovation is not considered a component of New Zealand national identity and that New Zealand's innovation identity is rooted in the nation's pioneering past. Our findings support the propositions made by Nakata and Sivakumar (1996) that low power distance, high individualism, low uncertainty avoidance, and low masculinity nations (New Zealand fits three of the four criteria) will be strong at the initiation phase of innovation but we also go further than Nakata and Sivakumar and elucidate more clearly why New Zealanders are good at this phase of innovation i.e., the nation's pioneering past in which New Zealanders had to make do with limited resources. Further, we have helped to identify potential areas that are limiting New Zealand in the implemenation phase of innovation. By identifying these factors, they can be targeted for improvement. Nations, including New Zealand, have the potential to overcome cultural deficits to innovation through public policy (Fukuyama 1995). The key is in identifying the deficit. Our research is highlighting important areas which need to be targeted by public policy initiatives.

In this article we focused on how New Zealand culture may play a role in national-level innovation success by influencing New Zealand innovators. In future research it would be prudent to look at how culture influences national innovation and economic policies as well as the structure of businesses within New Zealand. In this way a more integrated picture of how culture influences the many facets of New Zealand's innovation system can be garnered. Moving beyond New Zealand innovation, further research should also look at how culture influences innovation and economic policies in different nation-states.

\section{ACKNOWLEDGEMENTS}

Funding for this research was provided by the New Zealand Foundation for Research, Science and Technology under contract number LINX0801.

NOTES

1 As an increasing number of countries have been evaluated using Hofstede's measurements, the scale has been extended with some countries scoring above 100.

2 Likert-type scales are a commonly used psychometric scale. In the case of this research, respondents were asked to indicate the level of importance of cultural and national identity items on a four point, forced-choice scale.

3 An emphasis on egalitarianism is consistent with the low power distance found by Hofstede (1980). 


\section{REFERENCES}

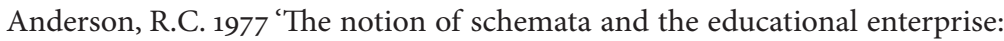
General discussion of the conference', in R.C. Anderson, R.J. Spiro \& W.E. Montague (Eds), Schooling and the Acquisition of Knowledge. Hillsdale, NJ: Lawrence Erlbaum: 415-431.

Andrew, J.P., DeRocco, E.S. and Taylor, A. 2009 The Innovation Imperative in Manufacturing: How the United States Can Restore its Edge, Boston: The Boston Consulting Group.

Blount, B.G. 2002 'Keywords, cultural models, and representations of knowledge: A case study from the Georgia coast', Coastal Anthropology Resources Laboratory Occasional Publication Number 3. Athens, GA: University of Georgia Department of Anthropology.

Borgatti, S.P. 1997 Consensus analysis, Analytic Tech, http://www.analytictech. com/borgatti/consensu.html

Budka, P. and Kremser, M. 2004 'CyberAnthropology-Anthropology of cyberculture', in S. Khittel, B. Plankensteiner and M. Six-Hohenbalken (Eds), Contemporary Issues in Socio-Cultural Anthropology: Perspectives and Research Activities from Austria. Vienna: Loecker:213-226.

Cooley, D.R. 2003 Cultural Models and Fishing Knowledge: A Case Study of Commercial Blue Crab Fisherman in Georgia, USA. PhD thesis, University of Georgia, Athens, GA.

D’Andrade, R. 1984 'Cultural meaning systems', in R.A. Schweder \& R.A. Levine (eds), Culture Theory: Essays on Mind, Self, and Emotion, Cambridge: Cambridge University Press: 88-119.

D’Andrade, R. 1995 The Development of Cognitive Anthropology, New York: Cambridge University Press.

Dressler, W.W., Balieiro, M.C. and Dos Santos, J.E. 1998 'Culture, socioeconomic status, and physical and mental health in Brazil', Medical Anthropology Quarterly, 12(4):424-446.

Fairweather, J. and Rinne, T. (under review) 'Computer-assisted, self interviewing (CASI) compared to face-to-face interviewing (FTFI) with open-ended, non- 
sensitive questions', International Journal of Qualitative Research Methods.

Fukuyama, F. 1995 Trust: The social virtues and the creation of prosperity, London: Hamish Hamilton.

Garro, L. 1986 'Intracultural variation in folk medical knowlegde: A comparison between curers and non-curers', American Anthropologist, 88(2):351-370.

Garro, L. 2000 'Remembering what one knows and the construction of the past: A comparison of cultural consensus theory and cultural schema theory', Ethos, 28(3):275-319.

Garro, L.C. 1988 'Explaining high blood pressure: Variation in knowledge about illness', American Ethnologist, 15(1): 98-119.

Geertz, C. 1973 The Interpretation of cultures, New York: Basic Books.

Godelier, M. 1971 'Salt currency' and the circulation of commodities among the Baruya of New Guinea, in G. Dalton (ed.) Studies in Economic Anthropology. Washington, DC: American Anthropology Association:376-379.

Goodenough, W.H. 1957 'Cultural anthropology and linguistics' in P. Garvin (Ed.), Report at The 7 th Annual Round Table Meeting on Linguistics and Language Study, Washington, Georgetown University Press.

Goodenough, W.H. 1961 'Comments on cultural evolution', Daedalus, 90:521-528.

Gregory, D. 2000 'Discourse', in R. J. Johnston, D. Gregory, G. Pratt \& M. Watts (Eds), Dictionary of Human Geography, Oxford: Blackwell.

Hall, E.T. 1990 Understanding Cultural Differences, Yarmouth, ME: Intercultural Press.

Hampden-Turner, C. and Trampenaars, A. 1993 The Seven Cultures of Capitalism: Value Systems for Creating Wealth in the United States, Japan, Germany, France, Britain, Sweden and the Netherlands, New York: Currency/Doubleday.

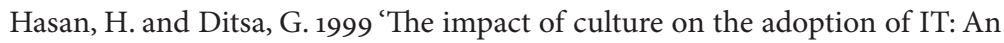
interpretive study', Journal of Global Information Management 7(1):5-15. 
Herbig, P.A. and Miller, J.C. 1992 'Culture and technology: Does the traffic move in both directions?', Journal of Global Marketing, 6(3):75-104.

Hofstede, G. 1980 Culture's Consequences: International Differences in Work Related Values, Beverly Hills, CA: Sage Publications.

Hofstede, G., and Bond, M.H. 1988 'The Confucius connection: From cultural roots to economic growth', Organizational Dynamics 16:5-21.

Hofstede, G., Hofstede, G.J. and Minkov, M. 2010 Cultures and Organizations: Software of the Mind, 3rd Edition. New York: McGraw Hill.

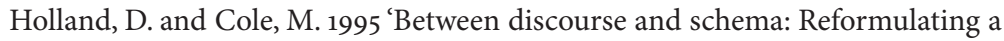
cultural-historical approach to culture and mind, Anthropology and Education Quarterly, 26(4):475-49o.

Holland, D. and Quinn, N. 1995 Cultural Models of Language and Thought, Cambridge: Cambridge University Press.

INSEAD 2009 Global Innovation Index 2008-2009, INSEAD, New York.

James, A. 2005 'Demystifying the role of culture in innovative regional economies', Regional Studies, 39(9):1197-1216.

Jin, D. 2001 The Dynamics of Knowledge Regimes: Technology, Culture and Competitiveness in the USA and Japan, London: Continuum.

Keesing, R. M. 1972 'Paradigms lost: The new ethnography and the new linguistics', Southwestern Journal of Anthropology, 28:299-331.

Lipset, S. M. 1990 Continental Divide: The Values and Institutions of the United States and Canada, New York: Routledge.

Nakata, C. and Sivakumar, K. 1996 'National culture and new product development: An integrative review', The Journal of Marketing, 6o(1): 61-72.

OECD 2005 Governance of Innovation Systems, oECD, Paris.

OECD 2010 OECD Factbook, oECD, Paris 
Oram, R. 2001 'Brand New Zealand', Unlimited Magazine, 25 October http://unlimited.co.nz/unlimited.ns/default/brand-new-zealand

Piaget, J. 1926 The Language and Thought of the Child, London: Routledge \& Kegan Paul.

Pro Inno Europe 2009 European Innovation Scoreboard 2008: Comparative Analysis of Innovation Performance, UNU-MERIT, Maastricht.

Rinne, T., Steel, G.D. and Fairweather, J. (in press) 'Hofstede and Shane revisited: The role of power distance and individualism in national-level innovation success', Cross-Cultural Research.

Romney, A.K., Weller, S.C. and Batchelder, W.H. 1986 'Culture as consensus: A theory of culture and informant accuracy', American Anthropologist, 88:313-338.

Romney, A.K., Batchelder, W.H. and Weller, S.C. 1987 'Recent applications of cultural consensus theory', The American Behavioral Scientist, 31(2):163-177.

Rusciano, F.L. 2003 'The construction of national identity - A 23 nation study' Political Research Quarterly, 56(3):361-366.

Saxenian, A. 1994 Regional Advantage: Culture and Competition in Silicon Valley and Route 128, Cambridge, MA: Harvard University Press.

Shane, S. 1992 'Why do some societies invent more than others?'Journal of Business Venturing, 7:29-46.

Shane, S. 1993 'Cultural influences on national rates of innovation', Journal of Business Venturing, 8:59-73.

Smale, T. 2008 The Influence of National Culture on New Zealand's Innovation Outcomes, мBA thesis, Henley Management College, Reading, UK.

Smith, A. 1776 An Inquiry into the Nature and Causes of the Wealth of Nations, London: Methuen and Co., Ltd.

Statistics New Zealand, 2011 National population estimates: March 2011 quarter. Retrieved from http://www.stats.govt.nz/browse_for_stats/population/estimates_and_projections/NationalPopulationEstimates_HOTPMarıqtr.aspx 
Strauss, C. and Quinn, N. 1997 A Cognitive Theory of Cultural Meaning, Cambridge: Cambridge University Press.

Swora, M.G. 2003 'Using cultural consensus analysis to study sexual risk perception: A report on a pilot study', Culture, Health and Sexuality, 5(4):339-352.

Weber, M. 1958 The Protestant Ethic and the Spirit of Capitalism, New York: Free Press.

Weller, S.C. and Romney, A.K. 1988 'Qualitative Research Methods: Systematic Data Collection', Qualitative Research Methods Series 10, Newbury Park, CA:Sage Publications

Wind, J., Mahajan, V. and Bayless, J.L. 1990 The Role of New Product Models in Supporting and Improving the New Product Development Process: Some Preliminary Results, Cambridge, MA: The Marketing Science Institute.

Woolfolk, A.E. 1987 Educational Psychology, Englewood Cliffs, NJ: Prentice-Hall. 